\title{
Epidural Spinal Canal Angiolipoma
}

National Cancer Institute

\section{Source}

National Cancer Institute. Epidural Spinal Canal Angiolipoma. NCI Thesaurus. Code C5424.

An uncommon lipoma characterized by prominent vascularity that arises in the epidural space of the spinal canal. 